\title{
Psychosocial family-level mediators in the intergenerational transmission of trauma: Protocol for a systematic review and meta- analysis
}

\author{
Author names and affiliations \\ Emma Mew, $\mathrm{MPH}^{1}$ \\ Kate Nyhan, MLS ${ }^{2,3}$ \\ Jessica Bonumwezi, $\mathrm{MA}^{4}$ \\ Vanessa Blas ${ }^{5}$ \\ Hannah Gorman, BA ${ }^{6}$ \\ Rachel Hennein, BS ${ }^{7,8}$ \\ Kevin Quach ${ }^{5}$ \\ Nicola L. Hawley, PhD ${ }^{1}$ \\ Sarah R. Lowe, $\mathrm{PhD}^{6}$
}

1. Department of Chronic Disease Epidemiology, Yale School of Public Health, Yale University, New Haven, USA; 2. Harvey Cushing / John Hay Whitney Medical Library, Yale University, New Haven, USA. 3. Department of Environmental Health Sciences, Yale School of Public Health, Yale University, New Haven, USA; 4. Department of Psychology, Montclair State University, Montclair, USA; 5. Yale College, Yale University, New Haven, USA; 6. Department of Social and Behavioral Sciences, Yale School of Public Health, Yale University, New Haven, USA; 7. Department of Epidemiology of Microbial Diseases, Yale School of Public Health, Yale University, New Haven, USA; 8. Yale School of Medicine, Yale University, New Haven, USA.

\section{Corresponding author}

Emma J. Mew

emma.mew@yale.edu

Yale School of Public Health

60 College Street, New Haven, Connecticut, 06510, United States

Figures: 1

Tables: 1

Word count: 3974 words (excluding abstract, tables, figure, author statement, funding, competing interests, and references)

Abstract word count: 237 words

\section{Keywords}

Intergenerational trauma; meta-analysis; psychosocial mechanisms; household-level; causal diagram 
medRxiv preprint doi: https://doi.org/10.1101/2021.04.27.21256190; this version posted April 30, 2021. The copyright holder for this preprint

(which was not certified by peer review) is the author/funder, who has granted medRxiv a license to display the preprint in perpetuity. It is made available under a CC-BY-ND 4.0 International license .

Mew et al., 2021 | Medrxiv preprint - Version 27 April 2021

\section{ABSTRACT}

Introduction: Psychosocial factors within the family appear to play a critical role in mediating the intergenerational transmission of trauma; however, there has yet to be a review article that quantitatively synthesizes causal mechanisms across a diversity of trauma-types. This study aims to systematically consolidate the epidemiological research on family-level psychosocial mediators and moderators to ultimately produce causal diagram(s) in the intergenerational transmission of trauma.

Methods and analysis: We will identify epidemiological peer-reviewed publications, dissertations, and conference abstracts that measure the impact of at least one psychosocial family-level factor mediating or moderating the relationship between parental trauma exposure and a child mental health outcome. English, French, Kinyarwanda, and Spanish articles will be eligible. We searched MEDLINE, PsycINFO, PTSDpubs, Scopus and ProQuest Dissertations and Theses and will conduct forward citation chaining of included documents. Two reviewers will perform screening and data extraction independently. We will extract reported mediators, moderators, and relevant study characteristics for included studies. Findings will be presented using narrative syntheses, descriptive analyses, mediation meta-analyses, moderating metaanalyses, and causal diagram(s), where possible. We will also perform a risk of bias assessment for studies included in meta-analyses and will construct a funnel plot to assess publication bias.

Ethics and dissemination: Ethical approval is not needed for this review. Results will be presented at academic conferences and published in a peer-reviewed journal in hopes to inform the development and evaluation of resilience-building interventions.

PROSPERO registration number: registration ID \#251053. 
medRxiv preprint dol: https://doi.org/10.1101/2021.04.27.21256190; this version posted April 30, 2021. The copyright holder for this preprint (which was not certified by peer review) is the author/funder, who has granted medRxiv a license to display the preprint in perpetuity. It is made available under a CC-BY-ND 4.0 International license.

Mew et al., 2021 | Medrxiv preprint - Version 27 April 2021

ARTICLE SUMMARY

Strengths and limitations of this study

- This review will generate the first evidence-based causal diagrams) of psychosocial factors mediating and moderating the intergenerational transmission of trauma.

- Our methods are based on the Cochrane Handbook for Systematic Reviews and Joanna Briggs Institute scoping review methods manual.

- We developed a comprehensive search strategy in partnership with two medical research librarians.

- We will reduce likelihood of publication bias through forward citation chaining and including conference abstracts and dissertations.

- We will not cover all languages, which might contribute language bias.

3 
medRxiv preprint doi: https://doi.org/10.1101/2021.04.27.21256190; this version posted April 30, 2021. The copyright holder for this preprint

(which was not certified by peer review) is the author/funder, who has granted medRxiv a license to display the preprint in perpetuity. It is made available under a CC-BY-ND 4.0 International license .

Mew et al., 2021 | Medrxiv preprint - Version 27 April 2021

\section{INTRODUCTION}

Intergenerational, or transgenerational, trauma is the process by which families with unresolved trauma transmit their trauma to descendants by influencing child mental development and wellbeing. ${ }^{1-4}$ This results in subsequent generations experiencing the psychological effects of trauma without exposure to it. This phenomenon has been documented in the psychological, anthropological, and social work disciplines over the past few decades, and interest has grown in recent years within the medical and public health communities. ${ }^{13}$ Most studies to date have focused on the descendants of Holocaust survivors, ${ }^{5}$ whereas smaller bodies of literature have included other populations and traumatic events, including indigenous populations, survivors of sexual assault, survivors of child maltreatment, refugee and immigrant populations, veterans and prisoners of war, among others. ${ }^{2} 3$ 6-9

Epidemiological studies provide some evidence for the intergenerational transmission of trauma. Most of the evidence has focused on transmission of trauma-related symptoms from the first (G1) to the second (G2) generation. Researchers have evaluated associations through two main paths: (1) association between parental trauma exposure on child psychopathology; and (2) parental trauma-related symptoms on child psychopathology. One recent meta-analysis showed that being a child of a Holocaust survivor was modestly associated with increased PTSD symptoms (standardized mean difference $=0.43$ ) compared to controls, ${ }^{10}$ and another meta-analysis of studies across any population or trauma-type identified a significant association between parental PTSD symptoms and child PTSD symptoms $(r=0.31) .{ }^{11}$ One noteworthy study demonstrated a statistically significant dose-response relationship between maternal lifetime PTSD symptoms and child PTSD in a cohort of 15,377 mothers and children (relative risks of 1.2 for 1-3 maternal symptoms, 1.3 for 4-5 maternal symptoms, and 1.6 for $6-7$ maternal symptoms; all $p<0.001) .{ }^{12}$ However, evidence is mixed, as additional reviews have been less conclusive. ${ }^{13-16}$ Researchers also speculate transmission from $\mathrm{G} 1$ to the third (G3) generation. ${ }^{6}$ This is supported by animals models, which suggest possible transmission from G1 to the fourth (G4) generation. ${ }^{17}$ However, few epidemiological studies have evaluated transmission from G1 to G3 and the few that have obtained mixed results. 101819

In addition to empirically demonstrating intergenerational trauma, it would be helpful to identify the causal processes underpinning this phenomenon, at least from G1 to G2, as such findings could inform interventions aimed to prevent or mitigate the intergenerational transmission of trauma. Mediation studies examine the extent to which an intermediate variable (mediator) explains the effect of exposure on an outcome in an attempt to tease apart causal mechanisms. ${ }^{20}$ Mediation studies quantify both direct and indirect effects, meaning the effect of exposure on the outcome and the effect of the exposure on the outcome through a mediating variable. ${ }^{20}$ Epidemiological studies can also highlight potential moderators of interest, which examine the extent to which another variable (moderator) influences the degree of association between an exposure and an outcome. These relationships are often demonstrated visually through causal diagrams, most formally directed acyclic graphs (DAGs). DAGs can powerfully deduce causal relationships as they incorporate statistical approaches into a visual diagram. ${ }^{21}$ Figure 1 
medRxiv preprint doi: https://doi.org/10.1101/2021.04.27.21256190; this version posted April 30, 2021. The copyright holder for this preprint (which was not certified by peer review) is the author/funder, who has granted medRxiv a license to display the preprint in perpetuity. It is made available under a CC-BY-ND 4.0 International license .

Mew et al., 2021 | Medrxiv preprint - Version 27 April 2021

demonstrates simplified DAGs for the intergenerational transmission of trauma including mediation (Figure 1A) and moderation (Figure 1B) paths.

[Insert Figure 1 here]

Figure 1. Simplified directed acyclic graphs for the intergenerational transmission of trauma from first (G1) to second (G2) generation. Panel A). Single mediator model showing indirect, direct, and total effects. Panel B). Simple moderation model.

To date, evidence suggests several complex, multifaceted causal processes underpin the intergenerational transmission of trauma, most notably evidence for genetic and epigenetic modes of transmission. ${ }^{22-31}$ Although this research is promising, genetic and epigenetic mechanisms do not appear to fully account for transmission of trauma, suggesting the involvement of other psychosocial and interpersonal factors. ${ }^{32-37}$ Recent studies have provided some evidence that psychosocial factors that operate within the household play some role in mediating the intergenerational transmission of trauma, ${ }^{1} 3438$ with the strongest evidence supporting parenting behaviors, parental mental health symptoms, and attachment. ${ }^{134}$

Understanding the role of psychosocial factors within the family in mediating and moderating the intergenerational transmission of trauma is critical to develop household-level psychosocial interventions that prevent transmission among high-risk families. Some psychosocial interventions have been explicitly developed to prevent the intergenerational transmission of trauma or have been evaluated for this purpose; ${ }^{39-46}$ however, these interventions are heterogeneous in their theoretical and therapeutic approaches and in evidence used to inform development. ${ }^{39}$ In addition, few interventions have been evaluated, and those that have often evaluate their impact on parenting behaviors rather than child mental health outcomes. ${ }^{39} 41$ Elucidating the mediating mechanisms that most strongly influence transmission would aid the selection of surrogate endpoints for child mental health outcomes for future studies. Understanding mediating and moderating factors could also optimize existing interventions, helping researchers understand what intervention component(s) are most effective and in what context(s).

To assess the need for a systematic review on this topic, ${ }^{47}$ we conducted a preliminary search to identify relevant literature reviews (eTable1). We located 12 reviews, most of which were scoping reviews focused on narrow sub-populations and trauma-event types (eTable 2). Only two reviews conducted moderation meta-analyses, ${ }^{11} 48$ but one was restricted to mothers with childhood maltreatment and the other only included studies published until 2011. Based on these findings: (1) no review has published a diagram to demonstrate and contextualize epidemiological causal relationships at the family-level in the intergenerational transmission of trauma; (2) no review has meta-synthesized family-level mediators; and (3) there is a need to perform an updated metaanalysis of family-level moderators across diverse trauma-types.

We aim to fill these gaps by systematically consolidating the family-level psychosocial mediators, their respective direct and indirect effects, and moderators of such effects, on the 
medRxiv preprint doi: https://doi.org/10.1101/2021.04.27.21256190; this version posted April 30, 2021. The copyright holder for this preprint (which was not certified by peer review) is the author/funder, who has granted medRxiv a license to display the preprint in perpetuity. It is made available under a CC-BY-ND 4.0 International license .

Mew et al., 2021 | Medrxiv preprint - Version 27 April 2021

intergenerational transmission of trauma. We will focus on a broad scope of populations and trauma types to increase the sample size available for meta-synthesis and to understand the general mechanisms underlying this phenomenon. We will also include impacts on the third generation (G3). By using the consolidation and meta-synthesis of epidemiological data, we will generate the first causal diagram to describe mechanisms through which trauma is transmitted intergenerationally.

The review questions are as follows:

(1) What family-level psychosocial mediator(s) and family-level psychosocial and demographic moderator(s) have epidemiological evidence supporting their involvement in the intergenerational transmission of trauma?

(2) What are the combined quantitative effects across mediators in the intergenerational transmission of trauma? Specifically:

a. What are the relationships between parental trauma and each mediator?; and

b. What is the indirect effect of parental trauma on child mental health via these mediators?

(3) What are the combined quantitative effects across moderators in the intergenerational transmission of trauma? Specifically:

a. How would each moderator impact the strength of relationship between parental trauma on child mental health?

\section{METHODS AND ANALYSIS}

This systematic review will employ a hybrid scoping and systematic review approach. Given the exploratory nature of our first research question (i.e., to identify and consolidate concept(s) into a causal diagram), this study will have elements that follow a scoping review approach. However, since our second question aims to meta-synthesize effect estimate(s), this review will also follow a systematic review approach.

This project will follow scoping review guidelines from the Joanna Briggs Institute 4749 and systematic review guidelines from the Cochrane Handbook for Systematic Reviews. ${ }^{50}$ We followed the PRISMA-P51 (eTable 3) and PRISMA-ScR ${ }^{52}$ reporting guidelines to develop this protocol and will follow PRISMA, ${ }^{53}$ PRISMA-ScR, and PRISMA for Children ${ }^{54}$ when writing the final review. We will use the MOOSE ${ }^{55}$ guideline to report our meta-analytic results. This study has been registered on PROSPERO (registration ID \#251053) and posted as a preprint on medRxiv. We will post detailed project materials, resources, statistical code, and protocol amendments on our Open Science Framework webpage (https://osf.io/k5ezm/).

\section{Protocol registration and timeline}

Preliminary searching and development of the search strategy occurred from July 2020 to March 2021. Reviewer training occurred from January to February 2021. Title/abstract screening is ongoing (having begun in March 2021) and is anticipated to finish in August 2021. Full-text screening will finish in December 2021. Data extraction, data charting, and meta-analyses will finish in June 2022. We anticipate submitting the manuscript for publication in August 2022. 
medRxiv preprint doi: https://doi.org/10.1101/2021.04.27.21256190; this version posted April 30, 2021. The copyright holder for this preprint (which was not certified by peer review) is the author/funder, who has granted medRxiv a license to display the preprint in perpetuity. It is made available under a CC-BY-ND 4.0 International license .

Mew et al., 2021 | Medrxiv preprint - Version 27 April 2021

\section{Eligibility criteria}

We will use the systematic review PICOTS (Population, Intervention, Comparator, Outcome, Timeframe, Study design) framework to define eligibility, adapted to accommodate our research question focused on observational studies reporting meditator(s) and/or moderator(s) (Table 1). Definitions/elaborations documents will be available on Open Science Framework (https://osf.io/k5ezm/).

\begin{tabular}{|l|l|}
\hline $\begin{array}{l}\text { Inclusion } \\
\text { concept }\end{array}$ & Eligibility criteria \\
\hline Population & - $\quad$ Human population \\
\hline Exposure & - $\begin{array}{l}\text { At least one primary caregiver (G1) who experienced a traumatic event and their child } \\
\text { (G2) and/or grandchild (G3) who did not experience this traumatic event } \\
\text { The traumatic event in G1 must have occurred before or during the birth of the child under } \\
\text { study }\end{array}$ \\
\hline $\begin{array}{l}\text { Mediator or } \\
\text { moderator }\end{array}$ & $\begin{array}{l}\text { Psychosocial factor(s) operating at the family-level that influence the interpersonal } \\
\text { relationship between the child and their immediate family and/or primary caregiver before } \\
\text { the child has reached 18 years of age. Factors can be a mediator or moderator } \\
\text { Comparators will be defined as the absence, or varying levels, of factor(s) measured in at } \\
\text { least some sub-group of participants }\end{array}$ \\
\hline Outcome & - $\begin{array}{l}\text { Quantitative measurement of at least one total, direct, or indirect effect of trauma } \\
\text { (psychological symptoms/functioning) in the child under observation at any point during } \\
\text { the child's lifespan (including >18 years old) }\end{array}$ \\
\hline $\begin{array}{l}\text { Timeframe and } \\
\text { language }\end{array}$ & $\begin{array}{l}\text { No date restrictions, but limited to English, French, Kinyarwanda, and Spanish languages } \\
\text { (research team members are fluent in these languages) }\end{array}$ \\
\hline $\begin{array}{l}\text { Study design } \\
\text { and document } \\
\text { type }\end{array}$ & $\begin{array}{l}\text { Original research article of a quantitative or mixed methods study published in journals, } \\
\text { dissertations (any level), or conference abstracts }\end{array}$ \\
\hline
\end{tabular}

Table 1. Eligibility criteria for systematic review.

\section{Population and Exposure(s)}

Included studies will have a population composed of at least one primary caregiver (G1) who experienced a traumatic event and their child (G2) and/or grandchild (G3) who did not experience this traumatic event firsthand. The G1 individual would not need to directly report their traumatic exposure, as long as there is some method to assess this, such as indirect reporting by G2. The method of reporting is unlikely to impact our results as one meta-analysis found that these measurement differences did not influence strength of intergenerational transmission. ${ }^{11}$ The traumatic event in G1 must have occurred before the birth of G2. G1 or G2 generation parents do not need to be biologically related to the child of interest. We will include trauma-exposed parents regardless of their trauma-related symptomatology. Animal studies will be excluded.

A traumatic event will be defined as exposure to threatened death, serious injury, or sexual violence, as outlined in the Diagnostic and Statistical Manual of Mental Disorders and previous literature. ${ }^{5657}$ This exposure may occur directly or indirectly to the individual, such as witnessing the event directly, learning the event occurred in a loved one, or repeated confrontation with aversive details of such event. ${ }^{56}$ Examples of a traumatic event might be, but are not limited to 
medRxiv preprint doi: https://doi.org/10.1101/2021.04.27.21256190; this version posted April 30, 2021. The copyright holder for this preprint (which was not certified by peer review) is the author/funder, who has granted medRxiv a license to display the preprint in perpetuity. It is made available under a CC-BY-ND 4.0 International license .

Mew et al., 2021 | Medrxiv preprint - Version 27 April 2021

first-hand or indirect experience of genocide, war, imprisonment, childhood abuse, cultural/historical trauma, sexual violence, and natural disaster. We will also consider parental trauma-related symptoms as the exposure, contingent that these symptoms are a direct result of an eligible traumatic exposure.

Mediator(s) and moderator(s)

Included studies will have at least one psychosocial factor operating at the family-level (including household- and parent-levels) that measured the interpersonal relationship between the child and their immediate family and/or primary caregiver before the child has reached 18 years of age. These could be framed or examined as mediators or moderators. Original articles would not need to explicitly use these terms or conceptualize factors in this way to be eligible.

Psychosocial factors might include parental psychiatric symptoms (such as anxiety, depression, distress, positive affect, or trauma-related symptomatology), suggesting that parental traumarelated mental health symptoms could be considered as the exposure or the mechanism, depending on the context. Factors might also include parental psychological factors (such as satisfaction, self-efficacy, self-esteem, and locus of control), interpersonal parent-child relationships (parental and family communication patterns and styles, family functioning and cohesion, emotional availability, parent-child attachment, decision-making, trauma communication, and abuse or neglect), or social factors within the household-level (which include demographic factors such as socioeconomic status, religion, age, gender, personal roles, and physical attributes) that would influence child-rearing behaviors, based on the Suzuki framework of psychosocial factors and traumatic events. ${ }^{58}$ Comparators will be defined the measurement of the absence of the factor(s) or varying levels of continuously-measured factor(s) of interest in at least some sub-group of participants in the study sample.

\section{Outcome(s)}

Included studies will quantify either the presence or absence of direct or indirect effects of trauma in the child (G2 or G3) under observation. Given the heterogeneity in clinical presentations of intergenerationally-transmitted trauma, ${ }^{59}$ we will only include quantitatively measured markers of psychological symptoms/functioning (i.e., child psychological development, psychopathology, and/or indicators of wellbeing). To increase our yield, we will be inclusive in what outcomes would qualify as child psychopathology and/or indicators of wellbeing for screening and may restrict this criterion after we assess the final sample of included studies; for instance, measures of child attachment will be eligible during screening, but if we find enough studies that measure child psychopathology directly to allow for at least one independent meta-analysis, we might restrict our sample to only these studies. Outcomes will be considered in offspring during all ages in their life (even $>18$ years of age). Symptoms of psychopathology in the child of interest would not need to be directly observed; for example, it would be acceptable for G1 to report psychopathology in G2 on their behalf.

Date and language restrictions 
medRxiv preprint doi: https://doi.org/10.1101/2021.04.27.21256190; this version posted April 30, 2021. The copyright holder for this preprint

(which was not certified by peer review) is the author/funder, who has granted medRxiv a license to display the preprint in perpetuity. It is made available under a CC-BY-ND 4.0 International license .

Mew et al., 2021 | Medrxiv preprint - Version 27 April 2021

This review will have no date restrictions but will be limited to studies published in English, French, Kinyarwanda, and Spanish languages, for feasibility, as research team members are fluent in these languages.

Study design and document type

We will include any epidemiologic study design, such as cross-sectional studies, case-control studies, cohort studies, randomized controlled trials, or the quantitative component of mixedmethods studies. Systematic review papers, meta-analyses, case-studies, qualitative studies, and study protocols will be excluded.

Due to feasibility, we will only include published literature (peer-reviewed literature and dissertations). One exception is that we will include conference abstracts during the screening phase contingent upon gaining access to the full text document (see Source of evidence selection). We included conference abstracts and dissertations to reduce publication bias. Previous research also suggests a low likelihood that we would identify additional studies outside of these sources, as one similar review ${ }^{1}$ did not identify relevant quantitative studies that were not peer-reviewed literature or dissertations.

\section{Searches}

The search strategy was developed and refined by a medical research librarian $(\mathrm{KN})$ with the assistance of the principal investigator (EM). The final search strategy was developed using the following Boolean logic: [intergenerational concept] AND [family level concept] AND [transmission of trauma concept] using appropriate keywords and controlled vocabulary.

We searched MEDLINE, PsycINFO, and PTSDpubs (formerly PILOTS) in January 2021. We also searched Scopus (conference papers only) and ProQuest Dissertations and Theses (doctoral dissertations only) in March 2021. eTables 4-8 shows the final search strategy for each bibliographic database. Although we only retrieved doctoral dissertations from Scopus, our PsycINFO search captured dissertations of all levels. The final search was peer-reviewed by a second medical librarian using the Peer Review of Electronic Search Strategies (PRESS) checklist before the search was finalized. ${ }^{60}$ We will re-run the search immediately before publication and screen additional records to ensure our results will be up to date.

We limited the search to five databases for feasibility given large search yields. However, to compensate for this limitation, we will implement three additional methods to increase sensitivity: (1) robust forward citation chaining of included studies; (2) reference list screening of relevant reviews from the authors' personal libraries; and (3) screening titles/abstracts of additional papers from the authors' personal libraries.

\section{Source of evidence selection}

Title/abstract and full-text screening will be performed independently by two reviewers. The principal investigator (EM) will be the second reviewer for all records. Discrepancies will be resolved through consensus or screening from a third reviewer. We will use Covidence software ${ }^{61}$ 
medRxiv preprint doi: https://doi.org/10.1101/2021.04.27.21256190; this version posted April 30, 2021. The copyright holder for this preprint (which was not certified by peer review) is the author/funder, who has granted medRxiv a license to display the preprint in perpetuity. It is made available under a CC-BY-ND 4.0 International license .

Mew et al., 2021 | Medrxiv preprint - Version 27 April 2021

for title/abstract screening and Google Forms ${ }^{62}$ for full-text screening. During full-text screening, we will record the primary reason for exclusion.

We will screen the full-text versions of conference abstracts during full-text review. For each conference abstract, we will first attempt to locate full-text document online. If that fails, we will send up to three emails to the corresponding author separated by at least one week requesting access to the full-text document. If we cannot obtain the full text using this process, we will exclude the record.

\section{Data extraction}

We will use Google Forms ${ }^{62}$ to extract data from included studies. Data will be extracted independently by two reviewers, as recommended. ${ }^{50}$ The principal investigator (EM) will be the second extractor for all records. Discrepancies will be resolved through consensus, and when needed, discussion with a third reviewer. To reduce multiple publication bias, we will de-duplicate the results of different individual studies reporting on the same underlying project into one study. We will use this combined information for our extraction and analyses. eTable 9 shows the drafted data extraction items. We modeled these items from similar reviews, ${ }^{1320}$ but they will likely be refined after piloting.

\section{Training and piloting procedures}

We held formal piloting and training procedures for reviewers before title/abstract screening, following training recommendations outlined in the Joanna Briggs Institute manual. ${ }^{47}$ Reviewers (EM, HG, JB, KQ, RH, SL, VB) first reviewed training materials, which included a draft definitions/elaborations document. We then underwent a series of training rounds to assess interrater reliability and identify discrepancies. In each round, reviewers independently screened a random sample of 25 records $^{63}$ from our final search yield to calculate percent agreement. Then, after each round, the team discussed discrepancies and modified the definitions/elaborations document. We repeated this process until we achieved team agreement of $>75 \%$, as suggested, ${ }^{63}$ and then began title/abstract screening.

We will follow similar procedures for full-text review training and data extraction piloting. Reviewers will first review training materials and draft definitions/elaborations document for fulltext screening. We will then undergo a series of training rounds where each reviewer will independently screen a batch of approximately 10 randomly selected records and extract data from included studies. Each round will be followed by discussion to modify screening procedures and the data extraction form. We will begin full-text screening after we achieve screening agreement of $>75 \% .^{63}$

Prior to beginning data extraction, EM will prepare and disseminate training materials for data extractors. Then, the team of data extractors will pilot data extraction and critical appraisal of 2-3 papers, discuss discrepancies, and repeat the process until achieving an agreement of $>75 \%{ }^{63}$ on each item before beginning extraction and appraisal.

\section{Data charting}


medRxiv preprint doi: https://doi.org/10.1101/2021.04.27.21256190; this version posted April 30, 2021. The copyright holder for this preprint

(which was not certified by peer review) is the author/funder, who has granted medRxiv a license to display the preprint in perpetuity. It is made available under a CC-BY-ND 4.0 International license .

Mew et al., 2021 | Medrxiv preprint - Version 27 April 2021

We will present summary information for all included studies in tabular format (eTable 10). We will then group the mediators presented in eTable 10 together into similar thematic concepts, through group discussion and consensus between the first and senior author. We will present these findings in a second table (eTable 11).

Causal diagram

We will use our findings in eTables 10 and 11 to develop at least one working causal diagram or framework. These diagram(s) will visually demonstrate the consolidated quantified relationships between variables and their relative magnitudes of association. We will include paths that are explicitly supported in our data and theoretical paths not explicitly supported (differentiated using solid versus dashed path lines). We will construct DAGs where possible if we obtain sufficient information, which would include combined effect estimates from our meta-analyses. ${ }^{64} 65$

We will generate different causal diagrams based on our findings. For example, we will consider producing different diagrams to demonstrate evidence for transmission from $G 1$ to $G 2$, G1 to G3, and $\mathrm{G} 2$ to G3. If there is enough quantity and quality of evidence to stratify our results across moderating concepts, we might also create additional diagrams stratified by relevant moderating levels. This could include graphs stratified by G1 gender, G2 gender, study design, among others.

\section{Meta-analyses}

Our statistical analysis plan is presented below with the understanding that our analytical strategies may be refined based on the distribution of data collected. Should there be significant methodological developments, we will incorporate new approaches with the input of statistical experts at the Yale School of Public Health.

We will conduct meta-analyses using a combination of SAS and R statistical software. We will consider a $p$-value $<0.05$ as sufficient evidence to reject a null hypothesis, but we will be holistic in our approach considering the raw $p$-values and other relevant statistical information.

Not all included studies will be eligible for meta-analysis. The principal investigator (EM) in consultation from the senior author (SL) will use information on the quality of reporting of results, the analyses conducted in the study, and the heterogeneity in exposures, mediators, moderators, and outcomes collected to decide what included studies will be eligible for meta-analyses.

Mediation meta-analyses

We will aim to use a mediation meta-analysis approach to pool data from individual mediation studies. Our primary analyses will assess the following pathway: parental trauma exposure $\rightarrow$ psychosocial mechanisms (including parental trauma-related symptoms) $\rightarrow$ child mental health outcome. We will also assess the following pathway: parental trauma-related symptoms $\rightarrow$ psychosocial mechanisms $\rightarrow$ child mental health outcome. We will conduct several metaanalyses according to each respective mediator and whether it mediated $G 1$ to $G 2$, G2 to G3, or G1 to G3 effects. We will conduct sensitivity analyses to test whether we could consolidate findings of individual studies with different study designs and consolidate individual studies that measured the exposure as parental trauma versus parental post-traumatic symptoms. We plan 
medRxiv preprint doi: https://doi.org/10.1101/2021.04.27.21256190; this version posted April 30, 2021. The copyright holder for this preprint (which was not certified by peer review) is the author/funder, who has granted medRxiv a license to display the preprint in perpetuity. It is made available under a CC-BY-ND 4.0 International license .

Mew et al., 2021 | Medrxiv preprint - Version 27 April 2021

to merge outcomes together to assess the global effect on child psychopathology; if there is enough data, we will sub-divide outcomes into different meta-analytic models. We will conduct meta-analyses following guidelines reported in the literature ${ }^{6667}$ that would be most suitable to for the methods reported in our sample of included studies.

Moderation meta-analyses

We will aim to use a moderation meta-analysis approach to pool moderator data from individual studies, using similar methods as described above. Our primary analyses will assess moderating effects on parental trauma exposure $\rightarrow$ child mental health outcome; our secondary analyses will assess moderating effects on parental trauma-related symptoms $\rightarrow$ child mental health outcome. We will perform moderation meta-analyses when we have at least two individual studies that measured all levels of the moderating concept and will conduct moderation meta-analyses using standard statistical methods. ${ }^{68}$

Critical appraisal

For studies included in any meta-analysis, we will assess the quality of all included articles using the Effective Public Health Practice Project Quality Assessment Tool for Quantitative Studies critical appraisal framework. ${ }^{56}$ This framework can be applied to a variety of study designs and generates an outputted numerical score, allowing for easier comparison between studies and calculation of inter-rater agreement. We will apply this framework at the study level and will integrate it into our data extraction methods. Discrepancies will be resolved through discussion and consensus, and when needed, consultation with a third reviewer. If we gather enough studies, we will conduct sensitivity analyses to assess whether study methodological quality impacts pooled estimates; if there are considerable differences, we will consider removing studies of "weak" quality.

Publication bias

We will also assess for publication bias using visual inspection of a funnel plot of studies included in the meta-analyses. It the plot is symmetrical we will conclude that publication bias is unlikely present.

Confidence in cumulative evidence

We will interpret our results using frameworks for causal inference ${ }^{69}$ to provide a narrative summary and recommendations for interventions.

\section{Ethics and dissemination}

This systematic review does not require ethical approval. We plan to publish the results of this review in an open-access peer-review journal (or one that encourages self-archiving) and present the findings at relevant academic conferences. We will also aim to produce a plain-language summary or infographic for knowledge users.

\section{Patient and public involvement}

We have not planned patient and public involvement in the design, interpretation, or dissemination of the findings. 
medRxiv preprint doi: https://doi.org/10.1101/2021.04.27.21256190; this version posted April 30, 2021. The copyright holder for this preprint (which was not certified by peer review) is the author/funder, who has granted medRxiv a license to display the preprint in perpetuity. It is made available under a CC-BY-ND 4.0 International license .

Mew et al., 2021 | Medrxiv preprint - Version 27 April 2021

\section{STRENGTHS AND LIMITATIONS}

Our methods are rigorous and follow the Cochrane Handbook for Systematic Reviews and Joanna Briggs Institute scoping review methods manual. We will take additional precautions to reduce likelihood of publication bias through forward citation chaining and including conference abstracts and dissertations. This review has several potential limitations. Although we consider our search strategy comprehensive, we only searched five databases and did not include Embase. We will not cover all languages, which might contribute language bias. We also might not locate enough studies to perform meta-analyses, although we predict this to be unlikely. Our causal diagrams(s) will be restricted to psychosocial household-level factors and will exclude other relevant mechanisms outside of this scope such as biological factors. This review will also be unable to assess complex causal relationships between mediators, moderators, and their respective interactions; however, we will include this information in our narrative synthesis and causal diagram(s) if this information happens to be reported in individual studies.

\section{CONCLUSION}

The development of evidence-based causal diagram(s) would provide more detailed understanding of the paths by which unresolved trauma can be transmitted intergenerationally at the family level, including the relative strength of each factor in mediating and moderating cause and effect. These results could then be applied to design and optimize evidence-based interventions that target mechanisms with the strongest mediating effect. Taken together, this review could provide evidence to better support interventions that interrupt the cycle of intergenerational trauma for future generations. 
medRxiv preprint doi: https://doi.org/10.1101/2021.04.27.21256190; this version posted April 30, 2021. The copyright holder for this preprint

(which was not certified by peer review) is the author/funder, who has granted medRxiv a license to display the preprint in perpetuity.

It is made available under a CC-BY-ND 4.0 International license .

Mew et al., 2021 | Medrxiv preprint - Version 27 April 2021

\section{AUTHOR STATEMENT}

EM and SL developed the study concept and question. EM provided project leadership and management. EM developed the initial draft of this protocol, with primary feedback from SL, and all authors reviewed and refined the protocol manuscript. KN and EM developed the search strategy. KN executed the search strategy. EM developed and revised the protocol for PROSPERO registration. EM is the guarantor of the review.

\section{FUNDING}

This research received no specific grant from any funding agency in the public, commercial or not-for-profit sectors. EM is supported by the Michael B. Bracken Doctoral Fellowship at the Yale School of Public Health and a Canadian Institutes of Health Research Doctoral Foreign Study Award. SL was supported by an Early-Career Research Fellowship from the Gulf Research Program of the National Academies of Sciences, Engineering, and Medicine; the content is solely the responsibility of the authors and does not necessarily represent the official views of the Gulf Research Program of the National Academies of Sciences, Engineering, and Medicine.

\section{COMPETING INTERESTS}

The authors declare no conflicts of interest. 
medRxiv preprint doi: https://doi.org/10.1101/2021.04.27.21256190; this version posted April 30, 2021. The copyright holder for this preprint

(which was not certified by peer review) is the author/funder, who has granted medRxiv a license to display the preprint in perpetuity. It is made available under a CC-BY-ND 4.0 International license .

Mew et al., 2021 | Medrxiv preprint - Version 27 April 2021

\section{REFERENCES}

1. Cerdeña JP, Rivera LM, Spak JM. Intergenerational trauma in Latinxs: A scoping review. Social Science \& Medicine 2021;270:113662.

2. Sangalang CC, Vang C. Intergenerational Trauma in Refugee Families: A Systematic Review. J Immigr Minor Health 2017;19(3):745-54.

3. Flanagan $N$, Travers $A$, Vallières $F$, et al. Crossing borders: a systematic review identifying potential mechanisms of intergenerational trauma transmission in asylum-seeking and refugee families. Eur J Psychotraumatol 2020;11(1):1790283-83.

4. Isobel S, Goodyear M, Furness T, et al. Preventing intergenerational trauma transmission: $A$ critical interpretive synthesis. Journal of clinical nursing 2019;28(7-8):1100-13.

5. Kellermann NP. Past, present and future perspectives of Holocaust trauma transmission. 2019.

6. Palacios JF, Portillo CJ. Understanding Native women's health: historical legacies. $J$ Transcult Nurs 2009;20(1):15-27.

7. Dekel R, Goldblatt $\mathrm{H}$. Is there intergenerational transmission of trauma? The case of combat veterans' children. Am J Orthopsychiatry 2008;78(3):281-9.

8. Barron IG, Abdallah G. Intergenerational Trauma in the Occupied Palestinian Territories: Effect on Children and Promotion of Healing. Journal of Child \& Adolescent Trauma 2015;8(2):103-10.

9. O'Neill L, Fraser T, Kitchenham A, et al. Hidden Burdens: a Review of Intergenerational, Historical and Complex Trauma, Implications for Indigenous Families. J Child Adolesc Trauma 2018;11(2):173-86.

10. Payne EA, Berle D. Posttraumatic stress disorder symptoms among offspring of Holocaust survivors: A systematic review and meta-analysis. Traumatology 2020.

11. Morris A, Gabert-Quillen C, Delahanty D. The Association Between Parent PTSD/Depression Symptoms and Child PTSD Symptoms: A Meta-Analysis. Journal of Pediatric Psychology 2012;37(10):1076-88.

12. Roberts AL, Galea S, Austin SB, et al. Posttraumatic stress disorder across two generations: concordance and mechanisms in a population-based sample. Biological Psychiatry 2012;72(6):505-11.

13. van IMH, Bakermans-Kranenburg MJ, Sagi-Schwartz A. Are children of Holocaust survivors less well-adapted? A meta-analytic investigation of secondary traumatization. J Trauma Stress 2003;16(5):459-69.

14. Lindert J, Knobler HY, Kawachi I, et al. Psychopathology of children of genocide survivors: a systematic review on the impact of genocide on their children`s psychopathology from five countries. Int J Epidemiol 2017;46(1):246-57.

15. Kellerman NP. Psychopathology in children of Holocaust survivors: a review of the research literature. Isr J Psychiatry Relat Sci 2001;38(1):36-46.

16. Diehle J, Brooks SK, Greenberg N. Veterans are not the only ones suffering from posttraumatic stress symptoms: what do we know about dependents' secondary traumatic stress? Soc Psychiatry Psychiatr Epidemiol 2017;52(1):35-44.

17. van Steenwyk G, Roszkowski M, Manuella F, et al. Transgenerational inheritance of behavioral and metabolic effects of paternal exposure to traumatic stress in early postnatal life: evidence in the 4th generation. Environmental epigenetics 2018;4(2):dvy023-dvy23.

18. Sagi-Schwartz $A$, van ljzendoorn $M$, bakermans-kranenburg $M$. Does intergenerational transmission of trauma skip a generation? No meta-analytic evidence for tertiary traumatization with third generation of Holocaust survivors. Attachment \& human development 2008;10:105-21. 
medRxiv preprint doi: https://doi.org/10.1101/2021.04.27.21256190; this version posted April 30, 2021. The copyright holder for this preprint

(which was not certified by peer review) is the author/funder, who has granted medRxiv a license to display the preprint in perpetuity. It is made available under a CC-BY-ND 4.0 International license .

Mew et al., 2021 | Medrxiv preprint - Version 27 April 2021

19. Scharf M. Long-term effects of trauma: psychosocial functioning of the second and third generation of Holocaust survivors. Dev Psychopathol 2007;19(2):603-22.

20. Lee H, Hübscher M, Moseley GL, et al. How does pain lead to disability? A systematic review and meta-analysis of mediation studies in people with back and neck pain. Pain 2015;156(6):988-97.

21. Glymour MM, Greenland S. Causal diagrams. Modern epidemiology 2008;3:183-209.

22. Yahyavi ST, Zarghami M, Marwah U. A review on the evidence of transgenerational transmission of posttraumatic stress disorder vulnerability. Braz J Psychiatry 2014;36(1):89-94.

23. Duncan LE, Ratanatharathorn A, Aiello AE, et al. Largest GWAS of PTSD $(\mathrm{N}=20070)$ yields genetic overlap with schizophrenia and sex differences in heritability. Molecular Psychiatry 2018;23(3):666-73.

24. Nievergelt CM, Maihofer AX, Klengel T, et al. International meta-analysis of PTSD genomewide association studies identifies sex- and ancestry-specific genetic risk loci. Nature Communications 2019;10(1):4558.

25. Bader HN, Bierer LM, Lehrner A, et al. Maternal Age at Holocaust Exposure and Maternal PTSD Independently Influence Urinary Cortisol Levels in Adult Offspring. Front Endocrinol (Lausanne) 2014;5:103-03.

26. Berkowitz GS, Wolff MS, Janevic TM, et al. The World Trade Center disaster and intrauterine growth restriction. Jama 2003;290(5):595-6.

27. Bierer LM, Bader HN, Daskalakis NP, et al. Elevation of 11 beta-hydroxysteroid dehydrogenase type 2 activity in Holocaust survivor offspring: evidence for an intergenerational effect of maternal trauma exposure. Psychoneuroendocrinology 2014;48:1-10.

28. Gapp K, Jawaid A, Sarkies $P$, et al. Implication of sperm RNAs in transgenerational inheritance of the effects of early trauma in mice. Nature Neuroscience 2014;17(5):66769.

29. Perroud N, Rutembesa E, Paoloni-Giacobino A, et al. The Tutsi genocide and transgenerational transmission of maternal stress: epigenetics and biology of the HPA axis. World J Biol Psychiatry 2014;15(4):334-45.

30. Yehuda R, Daskalakis NP, Bierer LM, et al. Holocaust Exposure Induced Intergenerational Effects on FKBP5 Methylation. Biol Psychiatry 2016;80(5):372-80.

31. Daskalakis NP, Xu C, Bader HN, et al. Intergenerational trauma is associated with expression alterations in glucocorticoid- and immune-related genes.

Neuropsychopharmacology 2021;46(4):763-73.

32. Berthelot N, Ensink K, Bernazzani O, et al. Intergenerational transmission of attachment in abused and neglected mothers: The role of trauma-specific reflective functioning. Infant mental health journal 2015;36(2):200-12.

33. Field NP, Muong S, Sochanvimean V. Parental styles in the intergenerational transmission of trauma stemming from the Khmer Rouge regime in Cambodia. Am J Orthopsychiatry 2013;83(4):483-94.

34. Fossion $\mathrm{P}$, Leys $\mathrm{C}$, Vandeleur $\mathrm{C}$, et al. Transgenerational transmission of trauma in families of Holocaust survivors: the consequences of extreme family functioning on resilience, sense of coherence, anxiety and depression. J Affect Disord 2015;171:48-53.

35. Roth M, Neuner F, Elbert T. Transgenerational consequences of PTSD: risk factors for the mental health of children whose mothers have been exposed to the Rwandan genocide. Int J Ment Health Syst 2014;8(1):12.

36. Wiseman H, Barber JP, Raz A, et al. Parental communication of Holocaust experiences and interpersonal patterns in offspring of Holocaust survivors. International Journal of Behavioral Development 2002;26(4):371-81. 
medRxiv preprint doi: https://doi.org/10.1101/2021.04.27.21256190; this version posted April 30, 2021. The copyright holder for this preprint

(which was not certified by peer review) is the author/funder, who has granted medRxiv a license to display the preprint in perpetuity. It is made available under a CC-BY-ND 4.0 International license .

Mew et al., 2021 | Medrxiv preprint - Version 27 April 2021

37. Wiseman H, Metzl E, Barber J. Anger, Guilt, and Intergenerational Communication of Trauma in the Interpersonal Narratives of Second Generation Holocaust Survivors. The American journal of orthopsychiatry 2006;76:176-84.

38. Dashorst P, Mooren TM, Kleber RJ, et al. Intergenerational consequences of the Holocaust on offspring mental health: a systematic review of associated factors and mechanisms. Eur J Psychotraumatol 2019;10(1):1654065-65.

39. Stephenson LA, Beck K, Busuulwa $P$, et al. Perinatal interventions for mothers and fathers who are survivors of childhood sexual abuse. Child Abuse and Neglect 2018;80:9-31.

40. Zayde A, Prout TA, Kilbride A, et al. The Connecting and Reflecting Experience (CARE): theoretical foundation and development of mentalizing-focused parenting groups. Attach Hum Dev 2020:1-17.

41. Colegrove VM, Havighurst SS, Kehoe CE, et al. Pilot randomized controlled trial of Tuning Relationships with Music: Intervention for parents with a trauma history and their adolescent. Child Abuse and Neglect 2018;79:259-68.

42. Murphy A, Steele H, Bate J, et al. Group attachment-based intervention: trauma-informed care for families with adverse childhood experiences. Fam Community Health 2015;38(3):268-79.

43. Cortizo R. Prenatal Broken Bonds: Trauma, Dissociation and the Calming Womb Model. $J$ Trauma Dissociation 2021;22(1):1-10.

44. Lawler J, Rosenblum K, Schuster M, et al. Mom Power: A Parenting Group Intervention for Mothers with Trauma Histories, 2018:165-80.

45. Annan J, Sim A, Puffer ES, et al. Improving Mental Health Outcomes of Burmese Migrant and Displaced Children in Thailand: a Community-Based Randomized Controlled Trial of a Parenting and Family Skills Intervention. Prev Sci 2017;18(7):793-803.

46. Scott KL, Copping VE. Promising directions for the treatment of complex childhood trauma: The Intergenerational Trauma Treatment Model. The Journal of Behavior Analysis of Offender and Victim Treatment and Prevention 2008;1(3):273-83.

47. Aromataris E MZ. JBI Manual for Evidence Synthesis. Secondary JBI Manual for Evidence Synthesis 2020. https://synthesismanual.jbi.global.

48. Su Y, D'Arcy C, Meng X. Intergenerational Effect of Maternal Childhood Maltreatment on Next Generation's Vulnerability to Psychopathology: A Systematic Review With MetaAnalysis. Trauma, violence \& abuse 2020:1524838020933870.

49. Peters MD, Marnie C, Tricco AC, et al. Updated methodological guidance for the conduct of scoping reviews. JBI Evidence Synthesis 2020;18(10):2119-26.

50. Higgins JP, Thomas J, Chandler J, et al. Cochrane handbook for systematic reviews of interventions: John Wiley \& Sons, 2019.

51. Moher D, Shamseer L, Clarke M, et al. Preferred reporting items for systematic review and meta-analysis protocols (PRISMA-P) 2015 statement. Systematic reviews 2015;4(1):1-9.

52. Tricco AC, Lillie E, Zarin W, et al. PRISMA extension for scoping reviews (PRISMA-ScR): checklist and explanation. Annals of internal medicine 2018;169(7):467-73.

53. Page MJ, McKenzie JE, Bossuyt PM, et al. The PRISMA 2020 statement: an updated guideline for reporting systematic reviews. BMJ 2021;372:n71.

54. Kapadia MZ, Askie L, Hartling L, et al. PRISMA-Children (C) and PRISMA-Protocol for Children (PC) Extensions: a study protocol for the development of guidelines for the conduct and reporting of systematic reviews and meta-analyses of newborn and child health research. BMJ open 2016;6(4):e010270.

55. Stroup DF, Berlin JA, Morton SC, et al. Meta-analysis of observational studies in epidemiology: a proposal for reporting. Meta-analysis Of Observational Studies in Epidemiology (MOOSE) group. Jama 2000;283(15):2008-12. 
medRxiv preprint doi: https://doi.org/10.1101/2021.04.27.21256190; this version posted April 30, 2021. The copyright holder for this preprint (which was not certified by peer review) is the author/funder, who has granted medRxiv a license to display the preprint in perpetuity. It is made available under a CC-BY-ND 4.0 International license.

Mew et al., 2021 | Medrxiv preprint - Version 27 April 2021

56. Benjet C, Bromet E, Karam EG, et al. The epidemiology of traumatic event exposure worldwide: results from the World Mental Health Survey Consortium. Psychological medicine 2016;46(2):327-43.

57. Association AP. Diagnostic and statistical manual of mental disorders (DSM-5®): American Psychiatric Pub, 2013.

58. Suzuki S-i, Takei Y. Psychosocial Factors and Traumatic Events. In: Gellman MD, Turner JR, eds. Encyclopedia of Behavioral Medicine. New York, NY: Springer New York, 2013:1582-83.

59. Wilk P, Maltby A, Cooke M. Residential schools and the effects on Indigenous health and well-being in Canada-a scoping review. Public Health Reviews 2017;38(1):8.

60. McGowan J, Sampson M, Salzwedel DM, et al. PRESS Peer Review of Electronic Search Strategies: 2015 Guideline Statement. Journal of Clinical Epidemiology 2016;75:40-46.

61. Covidence software. Secondary Covidence software. https://www.covidence.org/.

62. Google Forms. 2021. https://www.google.ca/forms/about/.

63. Joanna Briggs Institute. Chapter 11: Scoping Reviews 11.2.6 Source of Evidence Selection. Secondary Chapter 11: Scoping Reviews 11.2.6 Source of Evidence Selection 2020. https://wiki.jbi.global/display/MANUAL/11.2.6+Source+of+evidence+selection .

64. Ferguson KD, McCann M, Katikireddi SV, et al. Evidence synthesis for constructing directed acyclic graphs (ESC-DAGs): a novel and systematic method for building directed acyclic graphs. International Journal of Epidemiology 2019;49(1):322-29.

65. Williams TC, Bach CC, Matthiesen NB, et al. Directed acyclic graphs: a tool for causal studies in paediatrics. Pediatric Research 2018;84(4):487-93.

66. Cheung MW-L, Chan W. Meta-analytic structural equation modeling: a two-stage approach. Psychological methods 2005;10(1):40.

67. Shadish WR. Meta-analysis and the exploration of causal mediating processes: A primer of examples, methods, and issues. Psychological Methods 1996;1(1):47.

68. Lipsey MW, Wilson DB. Practical meta-analysis: SAGE publications, Inc, 2001.

69. Rothman KJ, Greenland S. Causation and causal inference in epidemiology. American journal of public health 2005;95(S1):S144-S50. 


\section{Exposure}

(G1 exposure to

traumatic event)

\section{Exposure}

(G1 exposure to traumatic event)

B.

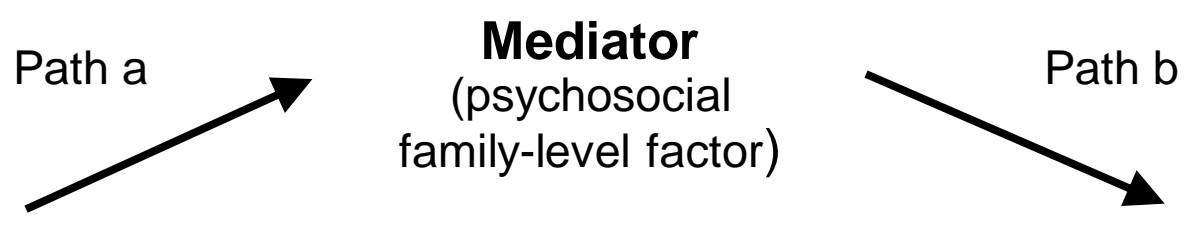

\section{Direct Effect}

Path c

\section{Total Effect}

\section{Outcome}

(G2 mental health outcomes)

\section{Exposure}

(G1 exposure to traumatic event)

\section{Moderator}

(psychosocial

family-level factor)

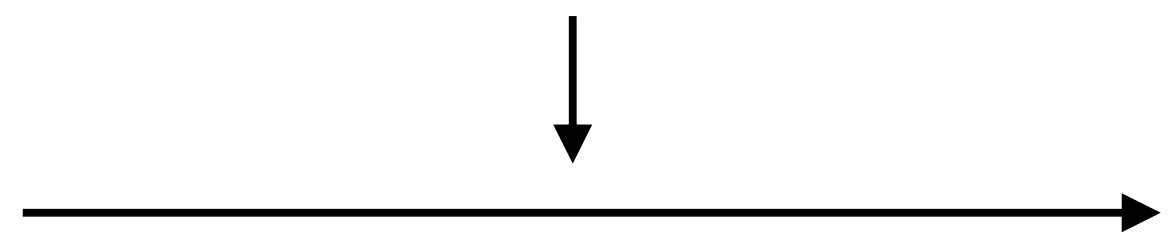

Outcome

(G2 mental health outcomes) 